\title{
К ВОПРОСУ ОБ ЭЛИТАРНЫХ ОСНОВАНИЯХ ЛИБЕРАЛЬНЫХ ДЕМОКРАТИЙ \\ (критические заметки на книгу: Higley J., Burton M. Elite Foundations of Liberal Democracy. Lanham; Boulder; New York; Toronto; Oxford: Rowman \& Littlefield Publishers, 2006. 227 p.)
}

\author{
B.A. Гymopos $^{1}$ \\ (gut-50@mail.ru) \\ Санкт-Петербургский государственный университет, \\ Санкт-Петербург, Россия
}

Цитирование: Гуторов В.А. К вопросу об элитарных основаниях либеральных демократий (критические заметки на книгу: Higley J., Burton M. Elite Foundations of Liberal Democracy. Lanham; Boulder; New York; Toronto; Oxford: Rowman \& Littlefield Publishers, 2006. 227 р.) // Власть и элиты. 2020. Т. 7, № 2. С. 176-191.

DOI: https://doi.org/10.31119/pe.2020.7.2.8

Аннотация. Цель статьи состоит в критической оценке и анализе концепиии американских политологов Джона Хигли и Майкла Бертона, разработанной в книге, которая посвящена проблемам генезиса, основных этапов эволюичи и практическим аспектам политики либеральных элит, играющцх ключевую роль в формировании современного мирового политического порядка. Анализ структуры и основных направлений современных политологических исследований отчетливо свидетельствует о том, ито проблемы эволюиии политических элит по-прежнему рассматриваются учеными в качестве наиболее приоритетных. Сущность позици Хигли и Бертона состоит в том, что в историческом плане либеральные политические элиты практически всегда формируются до того, как либеральные демократические принципы и практики будут приняты большим числом граждан. Сам комплекс взаимодействия политического поведения и институтов, составляющих либеральную демократию, является в первую очередь результатом творчества элиты, к которому постепенно и медленно присоединяются публичные массы. Консенсусно объединенные

${ }^{1}$ Статья подготовлена при поддержке Российского фонда фундаментальных исследований и Экспертного института социальных исследований, проект № 20-011-31349 «Либеральная традиция и ценности в современном мире: основные тенденции трансформации». 
элиты формировались нечасто в современной истории, и мало оснований полагать, что они станут менее редкими в нашем новом столетии. Разрозненные элиты, порождаюшие авторитарные режимы или нелиберальные демократии, исторически были правилом и, вероятно, останутся таковыми. В статье последовательно проводится точка зрения, согласно которой кризис либерализма как ведущей глобальной идеологии и его трансбормаиия на рубеже XX-XXI вв. в направлении авторитарно ориентированных неолиберальных практик, породил в качестве ответной реакиии рост интереса к политической философии неомакиавеллизма, одной из главных мишеней которого с середины ХХ в. были многочисленные мифь, формировавшиеся вокруг идеи демократии на протяжении многих столетий. В этом плане становится вполне понятным и стремление современных специалистов рассматривать макиавеллиевский реализм в его обновленной версии в качестве своеобразной аналитической матрии,ь, позволяюшей заново оценить с научных позиций как многообразные попытки кониептуализации власти, сбормировавшиеся за последние несколько десятилетий, так и новейшие модели глобального управления.

Ключевые слова: политические элиты, демократия, либерализм, глобальный мировой порядок, неомакиавеллизм, консервативная традииия, политическая власть.

Анализ структуры и основных направлений современных политологических исследований отчетливо свидетельствует о том, что проблемы эволюции политических элит по-прежнему рассматриваются учеными в качестве наиболее приоритетных. Современная Россия в этом плане, конечно, не является исключением. Как отмечают Джон Хигли и Майкл Бертон, «в ходе одного из великих политических изменений двадцатого века идеологически сплоченная элита, которая контролировала Советский Союз почти семь десятилетий, распалась между 1989 и 1991 годами, а в последние дни 1991 года СССР прекратил свое существование. Как и положено такому знаменательному событию, его причины и последствия являются предметом обширной литературы, в которой в качестве движущей силы преимущественно изображается окостенение советской элиты и быстро углубляющиеся трещины внутри неe» [Higley, Burton 2006: 188]. Разумеется, аналитика причин кризиса и трансформации советской элиты рассматривается Хигли и Бертоном в широком контексте современных теоретических дискуссий, посвященных различным аспектам генезиса и основных направлений эволюции и модификаций элитарной политики в различных регионах мира. В этом плане работа американских ученых, безусловно, является «знаковой». 
Для подтверждения данного тезиса необходимо, на наш взгляд, воспроизвести несколько наиболее принципиальных авторских позиций, характеризующих историческую и теоретическую платформу анализируемой работы. В работе Хигли и Бертона достаточно подробно характеризуется генетическая и функциональная роль, которую исторически играла либеральная демократия в процессе формирования и сохранения консенсусно объединенной элиты в различных западных странах. При этом ученых интересует прежде всего следующий вопрос: как формируется подобный тип элиты в различных регионах мира и в чем причины его относительной устойчивости?

Авторы признают, что «сама по себе данная связка (или взаимосвязь) отнюдь не является новой. Начиная с Джозефа Шумпетера в 1940-х годах такие социологи и политологи, как Роберт Даль, Джованни Сартори, Сеймур Мартин Липсет, Данкварт Ростоу, Хуан Линц, Альфред Степан, Роберт Патнэм, Ларри Даймонд и многие другие, писали о либеральной демократии или ее близких родственниках, например консолидированной демократии, подчеркивая важность внутренней приспособляемости и безопасности политической элиты. Многие исследователи “третьей волны” перехода к демократии также подчеркивали центральную роль стратегий, выбора и пактов элиты в таких переходах» [Higley, Burton2006: 2].

Тем не менее широко распространено двойственное мнение об относительной важности элиты для либеральной демократии по сравнению с массовой ее основой. Например, изучая демократизацию tout court, С.П. Хантингтон описывает убеждения и действия элит как «наиболее непосредственную и важную объясняющую переменную» для интерпретации волн демократизации, но он перечисляет также двадцать семь дополнительных переменных, которые влияют на причинно-следственные цепочки. Хантингтон утверждает, что «ни одна переменная не является необходимой или достаточной и что каждый случай демократизации имеет уникальное сочетание множества причин» [Higley, Burton 2006: 3]. «Мы утверждаем, - пишут Хигли и Бертон, - что в либеральной демократии элита и масса более разделены и долговременны в плане устойчивости. Политическая элита, члены и фракции которой настроены к взаимоуважительному и сдержанному политическому поведению, всегда формируется до того, как либеральные демократические принципы и практики будут приняты любым большим числом граждан. Сам комплекс взаимодействия политического поведения и институтов, составляющих либеральную демократию, является в первую очередь 
результатом творчества элиты, к которому постепенно и медленно присоединяются публичные массы. Это, конечно, тавтология: если элиты предпочитают практиковать либерально-демократическую политику, то либерально-демократическая политика будет практиковаться. Но известно, что элиты редко делают такой выбор. Консенсусно объединенные элиты формировались нечасто в современной истории, и мало оснований полагать, что они станут менее редкими в нашем новом столетии. Разрозненные элиты, порождающие авторитарные режимы или нелиберальные демократии, исторически были правилом и, вероятно, останутся таковыми. Сравнительно мало изучено, как возникает внутренне приспособляемая и безопасная политическая элита и почему она сохраняется. Отражая непреходящее влияние традиционной демократической мысли, элита, благоприятная для либеральной демократии, обычно рассматривалась как постепенный продукт социально-экономической модернизации, в результате которой демократические убеждения и ценности распространяются среди граждан и создаются все более активное гражданское общество и демократическая политическая культура. Считалось, что элитарное измерение либеральной демократии вытекает из ее массового измерения или неразрывно связано с ним. Мы, напротив, утверждаем, что в современной истории консенсусно объединенные элиты и, следовательно, либеральные демократии возникли всего тремя способами и при трех обстоятельствах» [Higley, Burton 2006: 3-4].

В плане сложившихся современных стереотипов все обозначенные учеными три обстоятельства выглядят не вполне привычными:

1. Урегулирование основных споров между враждующими элитами, которое является преднамеренным и внезапным и зависит от весьма условных обстоятельств и выбора элиты.

2. Колониальные возможности для местных элит проводить осторожную и ограниченную репрезентативную политику в течение длительных периодов самоуправления, а также руководить политически сложными движениями за национальную независимость.

3. Конвергенщии в сторону общих норм политического поведения разрозненных элит, борющихся за поддержку среди экономически процветающих электоратов [Higley, Burton 2006: 4].

По мысли Хигли и Бертона, такие совершенно особые обстоятельства, очевидно, были необходимы, для того чтобы в современный исторический период консенсусные объединенные элиты и стабильные 
репрезентативные либеральные олигархии и либеральные демократии возникли из чрезвычайно широко распространенной практики колониального правления. В основном эти обстоятельства были ограничены некоторыми британскими колониями, после того как английская политика была «приручена» и элиты применили аккомодационные методы в «водораздельных поселениях» образца 1689 г. «При нашем прочтении исторических данных относительно основ либеральной демократии английское поселение было стержневым политическим событием в новейшей истории. То, что это произошло в государстве Англия с Британией в качестве ядра, которое на протяжении продолжительного периода доминировало над значительной частью мира, имело огромные последствия в плане того, насколько мир политически эволюционировал в течение следующих трех столетий» [Higley, Burton 2006: 134-135].

Об этом свидетельствуют, в частности, аналогичные современные элитарные эксперименты, возникавшие при попытках спонтанного, нередко неосознанного до конца «творческого переосмысления» традиций британского «просвещенного колониализма». Например, во второй половине XX в. такого рода эксперименты были весьма популярны на территориях бывшей французской колониальной империи: «Как и сама Франция периода Пятой республики, которую Шарль де Голль основал в 1960 году, эти и несколько других бывших французских колоний создали президентские монархии, в которых разделение власти между новыми независимыми элитами не было широким, а представительный характер политики был незначительным. В лучшем случае можно говорить о зарождающемся либеральном, но в основном олигархическом режиме. Опасность заключалась в том, что, когда президентский монарх умирает или иным образом уходит с поста, элитная власть борется за контроль над высшим исполнительным органом. Это то, что в итоге произошло в Тунисе и Кот-д’Ивуаре» [Higley, Burton 2006: 133].

Все мы помним, какой популярностью среди российских политологов в 1990-е годы стали пользоваться неомакиавеллистские трактовки проблем власти, господства и принципов управления сразу после опубликования в посткоммунистической России перевода знаменитых лекций Реймона Арона «Демократия и тоталитаризм». Причины такой популярности были вполне очевидны: стремление осмыслить на уровне теории специфику посткоммунистических транзитов власти в странах Центральной и Восточной Европы, а затем и в самой России тре- 
бовало радикальной смены как идеологических, так и научных парадигм. Предпочтение при этом отдавалось преимущественно тем методологиям, в рамках которых осуществлявшаяся под лозунгами демократизации трансформация коммунистической олигархии в посткоммунистическую могла быть осмыслена на уровне «респектабельного понимания» основных тенденций современного мирового политического процесса, имманентно порождавших в условиях глобализации всеобщий кризис демократических институтов и традиций. В этом плане российским ученым не мог не импонировать, например, неомакиавеллистский взгляд на современные демократии, который Р. Арон вполне разделял: «Так называемые демократические режимы, как объясняют макиавеллисты, на деле не что иное, как олигархии особого рода - плутократические. Владельцы средств производства прямо или косвенно влияют на тех, кто вершит государственными делами. Итак, очевидный, принимаемый и макиавеллистами факт: режим, который в каком-либо смысле не был бь олигархическим, немьслим. Сама сущность политики такова, что решения принимаются для всего общества, но не им самим в целом. Решения и не могут приниматься сразу всеми. Народовластие не означает, что вся масса граждан непосредственно принимает решения о государственных финансах или внешней политике. Нелепо сопоставлять современные демократии с идеальными представлениями о неосуществимом режиме, при котором народ правит сам собой. Зато полезно сравнить существующие режимы с возможными. Это в равной мере относится к критике режимов советского типа с позиций макиавеллистов» [Арон 1993: 108-109].

В наши дни становится все более очевидным, что одной из главных мишеней политической философии неомакиавеллизма были многочисленные мифы, формировавшиеся вокруг идеи демократии на протяжении многих столетий. Так, по мнению Д. Крамера и Д. Олстеда, мифологическая оболочка демократических институтов сама по себе является свидетельством преобладания авторитарных стереотипов в общественном сознании и психологии. Следовательно, «современная демократия - это есть, по сути дела, попытка обуздать авторитаризм в области политики» [Крамер, Олстед 2002: 26]. Такого рода попытка вряд ли может быть реализована исключительно с помощью механизмов рационального убеждения с опорой на правовые институты.

Не следует, однако, забывать, что концепция Р. Арона изначально вписывалась в логику классической консервативной политической философии, вполне сформировавшейся уже к середине XIX в.: «Власть 
есть власть, как действительно говорил Токвиль: не имеет значения, находится ли она в руках одного человека, клики или всего народа. Она все равно остается властью и поэтому является репрессивной. Именно на этой изначально сформулированной Берком позиции, нашедшей немедленный отклик у де Местра и Бональда, возникает консервативный взгляд на природу народного правительства как на потенциально деспотическую. Соблазнительная мысль о том, что расширение базы власти автоматически означает уменьшение ее использования, поскольку народ де не способен тиранизировать сам себя, приведет, напротив, как утверждали консерваторы, к новой форме деспотизма, при котором весь народ или простое его большинство могут навязывать свою тираническую волю меньшинствам, творческим элитам и другим меньшим по объему общественным объединениям человеческих существ. Консерватор высмеивает руссоистско-якобинский взгляд на свободу, когда пишет: каждое утро гражданин, бреясь, будет глядеться в зеркало и видеть в своем лице одну десятимиллионную часть тирана и целиком раба» [Nisbet 1988: 47-48].

Спонтанно возникшая в начале XXI в. дискуссия о нелиберальной демократии особенно показательна в плане поразительной устойчивости консервативной социальной критики. Как отмечал, например, Р. Саква, «в недавней статье Фарид Закария имплицитно стал поддерживать точку зрения Реймона Арона относительно того, что концепция “конституционного плюрализма” во многих случаях более корректна, чем формула “либеральной демократии”. Закария устанавливает различие между либеральной демократией, определяемой как “политическая система, для которой характерны не только свободные и честные выборы, но и правовое государство, разделение властей и защита основополагающих свобод - слова, собраний, религии и собственности" (такую систему он называет конституционным либерализмом) и нелиберальной демократией. В последней “демократически избранные режимы (часто такие, которые были переизбраны и утвердили себя через референдумы) рутинно игнорируют конституционные ограничения своей власти и лишают своих граждан основных прав и свобод". Для Закарии регулярная постановка относительно честных, соревновательных, многопартийных выборов может сделать страну демократической, но она не обеспечит хорошее правление» [Sakwa 2001: 276].

В этот же период некоторые исследователи политической теории Антонио Грамши отмечали, что критика его последователями современного либерального порядка имеет много общего с критикой либе- 
рализма в консервативной философии Карла Шмитта. Действительно, Шмитт был ярым критиком либерального универсализма с его претензией на единственную подлинную и легитимную политическую систему. Для него «мир был множеством, а не вселенной, и он был непреклонен в том, что любая попытка навязать одну единственную модель во всем мире будет иметь ужасные последствия. В концепции политического он резко критиковал то, как либералы использовали понятие “человечества" в качестве идеологического оружия империалистической экспансии, и показал, как гуманитарная этика служит средством экономического империализма. <...> По его мнению, это объясняет, почему войны во имя человечества были особенно бесчеловечными, ибо все средства были хороши, чтобы представить врага “вне закона” человечества. Нынешнее определение границы между другом и врагом как границы между цивилизованным миром и его врагами, несомненно, было бы осуждено им как аватар либеральной риторики. <..> Несмотря на свою решимость, Шмитт был также явно впечатлен способностью американского империализма гарантировать интерпретацию решающих политических стратегических понятий, таких как мир, разоружение, порядок и общественная безопасность» [The International Political Thought of Carl Schmitt 2007: 148-149].

Обозначенные выше тенденции (равно как и специфика их интерпретаций) весьма характерны для неолиберальных порядков на Западе: гегемония элитных групп осуществляется в настоящее время не столько путем апелляции к либеральной традиции как таковой, но скорее при помощи активного использования медийных технологий, непосредственным результатом которых является возникновение ситуации квазилиберального манипулятивного консенсуса. Его сторонники постоянно настаивают на том, что традиционные идеологии исчерпали себя и их скоро сменит новая эра «постидеологии». Эти новые тенденции, несущие явную угрозу либеральной демократии, хорошо проанализированы в работах Энтони Ди Маджо. «Бизнес-группы, - отмечает Ди Маджо, - не контролировали новости открыто, их влияние ощущалось при помощи более тонких инструментов. Фактическая монополизация новостей правительственными чиновниками косвенным образом способствовала интересам бизнеса, так как журналисты, авторы, редакторы и эксперты действовали в рамках политико-экономической системы, которая все более враждебно относилась к организованному труду и повышению минимальной заработной платы, даже 
если время от времени такие повышения случайно и происходили. Таким образом, проправительственный уклон перерос в косвенный уклон в пользу бизнеса в общенациональном обсуждении вопроса о минимальной заработной плате. Из-за доминирования правительства в новостях некоторые точки зрения были в значительной степени исключены из обсуждения. <...> Представители бизнеса не доминировали в дискуссиях о Программе социального обеспечения и снижения налогов, но тем не менее гегемонистская предвзятость была очевидна. <...> Из-за правого дрейфа американской политики именно снижение налогов стало приоритетным направлением, а не расширение государственных услуг за счет увеличения налоговых поступлений и расходов. Эта тенденция предполагает, что гегемонистское мышление, благоволящее интересам богатых в отношении снижения налогов, все в большей степени стимулирует политический дискурс. <...> Позиция журналистов соответствовала мнению политических чиновников в том, что общественность вообще не должна быть замечена или услышана в дебатах о государственной политике. Общественность участвует в выборах на основе коллективного присутствия, но в обсуждении политики ее вклад сведен до минимума. Эта чрезвычайно ограниченная концепция “демократии” (если можно так ее назвать) рассматривает общественность как пассивную силу, управляемую политическими элитами. <...> Неужели гегемонистский уклон в новостях означает, что публика последовательно становилась жертвой мнения элит и бизнеса, а согласие масс просто фабриковалось? Я вижу мало доказательств этому. Разумеется, зачастую общественность склоняют с помощью индоктринации к поддержке позиций бизнеса, что всегда благоприятствует интересам богатых. Американцы могут быть классифицированы в качестве “полуавтономных” по отношению к партийной политической системе. Иногда послания политических чиновников в новостях оказывали значительное влияние на общественное мнение. В других случаях общественность не одобряла эти послания, если они не соответствовали их собственным предпочтениям и интересам. Общественное неприятие официальных повесток дня чаще встречается в отношении вопросов, по которым граждане обладают значительными предварительными знаниями и опытом, как показывают примеры реформ в области социального обеспечения и медицинской помощи» [DiMaggio 2017: 60, 88-90, 229-230].

Следует также отметить, что еще в конце 1980-х - начале 1990-х годов - периода, когда пропагандируемые Френсисом Фукуямой мифы 
о «конце истории» и «глобальном триумфе» либерализма достигли своего апогея, Аллан Блум, характеризуя общий контекст работы Фукуямы «Конец истории?», первоначально опубликованной в качестве эссе в «Национальных интересах», т.е. за три года до выхода в свет его знаменитой одноименной работы, предельно резко высказал свой глубокий скепсис относительно конечных перспектив либеральной демократии: «Либерализм победил, но он может быть решительно неудовлетворительным. Коммунизм был безумным продолжением либерального рационализма, и все видели, что он не работает и нежелателен. Хотя фашизм был побежден на поле битвы, его темные возможности не были поняты до конца. Если искать альтернативу, то искать ее больше негде. Я бы предположил, что у фашизма есть будущее, если не Грядущее. Многое из того, о чем говорит Фукуяма, указывает в этом направлении. И факты тоже. Африканские и ближневосточные народы, которые по какой-то причине не достигают успеха в современном мире, испытывают искушение найти смысл и самоутверждение в разновидностях мракобесия. Европейские нации, не находящие рациональных объяснений для закрытия своих стран от многочисленных иммигрантов, обращаются к своим национальным мифам. Американские левые с энтузиазмом восприняли фашистские аргументы против современности и евроцентризма, вписанные в контекст рационализма. Однако, возможно, именно Фукуяма познакомил прагматиков с необходимостью философии теперь, когда идеология мертва или умирает, для тех, кто хочет интерпретировать нашу изменившуюся ситуацию» [Bloom 1989: 21].

В этом плане становится вполне понятным и уже обозначенное выше стремление современных специалистов рассматривать макиавеллиевский реализм в его обновленной версии в качестве своеобразной аналитической матрицы, позволяющей заново оценить с научных позиций как многообразные попытки концептуализации власти, сформировавшиеся за последние несколько десятилетий, так и новейшие модели глобального управления, характеризующие основные параметры «нового мирового порядка». «Хотя власть и управление, - отмечает Стефано Гудзини в содержательной статье «Амбивалентная “диффузия власти” в глобальном управлении», - неразрывно связаны, есть веские причины воспринимать их концептуально разделенными. Одна из них - это то, что я называю “заблуждением-перегрузкой” (“overloadfallacy”) концептуального анализа власти, показывая, что в конечном итоге концепция власти становится просто громоздкой, когда ученые 
пытаются включить все аспекты анализа власти, от личной автономии до ее оснований, мотивов и влияния, от социального господства до безличного правления. Знания о структурной власти недостаточно для понимания структур власти (господства). И попытка объединить эти два понятия бесполезна и не может быть осуществлена без метатеоретических противоречий. Вторая причина больше связана с неявной философской предвзятостью, с которой осуществляется анализ, если при этом не проводится различие между властью и порядком. Власть вездесуща. Отсюда всего лишь небольшой шаг, чтобы поставить власть в центр понимания политики, а также политического порядка. И это почти самоочевидный шаг для определенных традиций политической теории, которые вдохновляются, но не сводятся к макиавеллистскому повороту в понимании политики, в таких его разновидностях, как политический реализм, марксизм, а также Фуко» [Guzzini 2012: 8].

По мнению Гудзини, чтобы понять, имело ли место распространение власти в глобальном управлении и привело ли это к ослаблению или усилению управления, важно в первую очередь уточнить понимание того, что мы подразумеваем под управлением и каким образом возможно интерпретировать современное значение этого понятия. «Это значение не является ни надуманным, ни очевидным, и, более того, напрямую связано с более широким анализом политики и власти. Дело не в том, что у нас есть “проблема управления", на которую разные теоретические подходы дают разные ответы; у нас есть разные теоретические подходы, которые придают разное значение управлению и его проблемам. В дальнейшем я предлагаю рассматривать управление в терминах “политического порядка”, где “политический” означает все, что затрагивает “общественные интересы” или “общее благо”. Это более широкое определение по сравнению с определениями, представленными в большинстве подходов. Тем не менее, как показывает обсуждение различных определений, оно прямо или косвенно присутствует во многих из них. Такое относительно не эксклюзивное определение оправдано, если не необходимо при сравнении и обсуждении альтернативных подходов, а не при представлении какого-либо одного из них» [Guzzini 2012: 3].

Обычно отправной точкой для определения управления является то, что этот термин сразу предлагает следующую ключевую дефиницию: «действия, совершаемые правительствами, но выполняемые кем-то другим или комбинацией действующих лиц» [Guzzini 2012: 4]. Данная 
дефиниция остается ориентированной на правительство и организует наше мышление вокруг парадигмы (государственного) управления для понимания политического порядка в международном сообществе. Определение управления с точки зрения порядка готовит почву для того, чтобы увидеть проблемные моменты, которые может вызвать распространение власти в международных делах. «Чтобы увидеть эту взаимосвязь, важно с самого начала разделять концептуальную сущность власти и управления. Другими словами, важно видеть, что управление и власть взаимосвязаны. Не менее важно, однако, не пытаться свести одно к другому. Хотя все формы видения порядка подразумевают формы восприятия власти, и наоборот. Порядок не сводится к власти, и наоборот» [Guzzini 2012: 6].

Существовала, продолжает Гудзини, постоянная тенденция объединять эти два понятия или сводить одно к другому. Когда Даль (1961) ответил на вопрос «Кто правит?», он действительно хотел понять тип политического строя - плюралистический или элитарный - в современной демократии. Ответ он получил из анализа власти. «Как сразу заметили критики, этого было недостаточно для объяснения политического порядка в целом. Тем не менее, вместо того чтобы разделять концепции и видеть, как они могут по-разному соотноситься друг с другом, критики также стремились сводить одно к другому и, следовательно, добавляли все больше и больше факторов в концепцию власти. «С помощью сравнительно близкого, хотя и несколько реверсивного подхода Лукс (1974) попытался концептуализировать власть как личную автономию в терминах трех измерений власти, то есть в терминах порядка, понимаемого как структура господства. Этот ход сравним с подходом Даля, потому что, опять же, анализ власти и анализ порядка сводятся друг к другу. Это делается в обратном порядке, поскольку теперь власть используется не для понимания порядка, а для понимания индивидуальной силы (автономии, свободы). Более того, Лукс, как и многие другие, иногда использует термин “власть” для всех этих уровней. Добавляя Фуко в этот резкий спор, Барнет и Дюваль (см.: [Barnett, Duvall 2005: 39-75]) просто следуют этому редукционистскому подходу: <..> глобальное управление - это то, что теперь можно понять с помощью четырех типов власти... А если это не так, то получается, что они оставляют управление в конечном итоге недооцененным, предлагая простую (и известную) типологию концепций власти» [Guzzini 2012: 7-8]. 
По мнению Гудзини, далеко не случайно, что подход Мишеля Фуко устанавливает теснейшую связь между формами власти (биовласть) и порядком (управляемость). «Но это еще не все, что нужно для политического порядка. В хорошем смысле социальных наук, пытающихся избавиться от нормативных забот политической философии, это может показаться так. Однако уже Карр знал, что чисто реалистический подход невозможен ни к политике в целом, ни к (тогдашнему) “новому международному порядку”, в частности: утопии, мораль или “общее благо” не могли быть сведены к власти, равно как не может к ней сводиться международный порядок. Порядок, безусловно, всегда существует для кого-то, но он также всегда означает что-то, какую-то ценность» [Guzzini 2012: 8].

Возвращаясь в свете этого анализа к проблемам политических элит, следует отметить, что сформировавшийся в последнее десятилетие синтетический методологический комплекс предоставляет новые возможности для объяснения причин, по которым, несмотря на традиционное преобладание либеральных идей и стереотипов в мировом политическом дискурсе, возникающие в современном мире элитные конфигурации, как правило, плохо совместимы с либеральной демократией в идеологическом и политическом плане. Как справедливо полагают Хигли и Бертон, «перспективы либеральной демократии в XXI веке зависят в первую очередь от формирования консенсусно объединенных элит там, где сейчас господствуют разобщенные или идеологически объединенные элиты, и от сохранения консенсусно объединенных элит там, где они сейчас существуют» [Higley, Burton 2006: 181].

\section{Литература}

Арон Р. Демократия и тоталитаризм. М.: Текст, 1993. 303 с.

Крамер Д., Олстед Д. Маски авторитарности. Очерки о гуру. М.: ПрогрессТрадиция, 2002. 408 с.

Barnett M., Duvall R. Power in International Politics // International Organization. 2005. 59 (1). P. 39-75.

Bloom A. Responses to Fukuyama // The National Interest. Summer. 1989. P. 19-21.

DiMaggio A. The Politics of Persuasion: Economic Policy and Media Bias in the Modern Era. Albany: State University of New York Press. 2017. 375 p.

Guzzini S. The Ambivalent "Diffusion of Power" in Global Governance // The Diffusion of Power in Global Governance: International Political Economy Meets Foucault. St. Guzzini, I. B. Neumann (eds.). L.: Palgrave Macmillan, 2012. P. 1-37. 
Higley J., Burton M. Elite Foundations of Liberal Democracy. Lanham; Boulder; N.Y.; Toronto; Oxford: Rowman \& Littlefield Publishers, 2006. 227 p.

Nisbet R. Conservatism: Dream and Reality. Minneapolis: University of Minnesota Press, 1988. 130 p.

Sakwa R. Liberalism and Post-communism // The Edinburgh Companion to Contemporary Liberalism. General Editor M. Evans. Edinburgh: Edinburgh University Press, 2001. P. 269 -286.

The International Political Thought of Carl Schmitt: Terror, Liberal War and the Crisis of Global Order. Ed. by L. Odysseos, F. Petito. L.; N.Y.: Routledge, 2007. 266 p.

\title{
ON THE QUESTION OF THE ELITE FOUNDATIONS OF LIBERAL DEMOCRACIES (critical notes on the book: Higley J., Burton M. Elite Foundations of Liberal Democracy. Lanham; Boulder; New York; Toronto; Oxford: Rowman \& Littlefield Publishers, 2006. 227 p.)
}

V. Gutorov ${ }^{1}$

\author{
(gut-50@mail.ru) \\ St. Petersburg State University, \\ St. Petersburg, Russia
}

Citation: Gutorov V. K voprosu ob elitarnykh osnovaniyakh liberal'nykh demokratiy (kriticheskiye zametki na knigu: Higley J., Burton M. Elite Foundations of Liberal Democracy. Lanham; Boulder; New York; Toronto; Oxford: Rowman \& Littlefield Publishers, 2006. 227 p.) [On the question of the elite foundations of liberal democracies (critical notes on the book: Higley J., Burton M. Elite Foundations of Liberal Democracy. Lanham; Boulder; New York; Toronto; Oxford: Rowman \& Littlefield Publishers, 2006. 227 p.)]. Vlast' i elity [Power and Elites], 2020, 7 (2): 176-191. (In Russian)

DOI: https://doi.org/10.31119/pe.2020.7.2.8

${ }^{1}$ The article was prepared with the support of the Russian Foundation for Basic Research and the Expert Institute for Social Research, project no. 20-011-31349 "Liberal tradition and values in the modern world: the main trends of transformation". 
Abstract. The purpose of the article is to critically assess and analyze the concept of American political scientists John Higley and Michael Burton, developed in a book that is devoted to the problems of genesis, the main stages of evolution and practical aspects of the politics of liberal elites that play a key role in the formation of the modern world political order. An analysis of the structure and main directions of modern political science studies clearly indicates that the problems of the evolution of political elites are still considered by scientists as the most priority ones. The essence of Higley and Burton's position is that, historically, liberal political elites almost always form before liberal democratic principles and practices are adopted by any large number of citizens. The very complex of interaction of political behavior and institutions that make up liberal democracy is, first of all, the result of the creativity of the elite, to which the public masses are gradually and slowly joining. Consensually united elites have formed infrequently in modern history, and there is little reason to believe they will become less rare in our new century. Scattered elites that spawn authoritarian regimes or illiberal democracies have historically been and are likely to remain the rule. The article consistently holds the point of view according to which the crisis of liberalism as a leading global ideology and its transformation at the turn of the XX-XXI centuries into the direction of authoritarian-oriented neoliberal practices, gave rise as a response to the growth of interest in the political philosophy of neoMachiavellianism, one of the main targets of which from the middle of the 20th century were numerous myths that formed around the idea of democracy over the centuries. In this regard, it becomes quite understandable and the aspiration of modern specialists to consider Machiavellian realism in its updated version as a kind of analytical matrix that allows to re-evaluate from a scientific standpoint both the various attempts to conceptualize power that have formed over the past few decades, and the latest models of global governance.

Keywords: political elites, democracy, liberalism, global world order, neoMachiavellianism, conservative tradition, political power.

\section{References}

Aron R. Demokratija i totalitarizm [Democracy and Totalitarianism]. Moscow: Text Publ., 1993. 303 p. (In Russian)

Barnett M., Duvall R. Power in International Politics. International Organization, 2005, 59 (1), pp. 39-75.

Bloom A. Responses to Fukuyama. The National Interest, Summer 1989, pp. 19-21. DiMaggio A. The Politics of Persuasion: Economic Policy and Media Bias in the Modern Era. Albany: State University of New York Press. 2017. 375 p.

Guzzini S. The Ambivalent "Diffusion of Power" in Global Governance. In: The Diffusion of Power in Global Governance: International Political Economy Meets Foucault. St. Guzzini, I. B. Neumann (eds.). London: Palgrave Macmillan, 2012, pp. 1-37. 
Higley J., Burton M. Elite Foundations of Liberal Democracy. Lanham; Boulder; New York; Toronto; Oxford: Rowman \& Littlefield Publishers, 2006. 227 p.

Kramer J., Alstad D. Maski avtoritarnosti. Ocherki o guru [Masks of Authoritarian Power. The Guru Papers] Moscow: Progress-Tradition, 2002. 408 p. (In Russian)

Nisbet R. Conservatism: Dream and Reality. Minneapolis: University of Minnesota Press, 1988. $130 \mathrm{p}$.

Sakwa R. Liberalism and Post-communism. In: The Edinburgh Companion to Contemporary Liberalism. General Editor M. Evans. Edinburgh: Edinburgh University Press, 2001, pp. 269-286.

The International Political Thought of Carl Schmitt: Terror, Liberal War and the Crisis of Global Order. Ed. by L. Odysseos, F. Petito. London; New York: Routledge, 2007. $266 \mathrm{p}$. 